\title{
New non-quinone geldanamycin analogs from genetically engineered Streptomyces hygroscopicus
}

\author{
Cheng-Zhu Wu ${ }^{1,2}$, An Na Moon ${ }^{3}$, Jae-Hyuk Jang ${ }^{1}$, Dongho Lee ${ }^{4}$, Sun-Young Kang ${ }^{1,5}$, Joon-Tae Park ${ }^{3}$, \\ Jong Seog Ahn ${ }^{1}$, Bang Yeon Hwang ${ }^{5}$, Young Ho Kim², Hong-Sub Lee ${ }^{3}$ and Young-Soo Hong ${ }^{1}$
}

The Journal of Antibiotics (2011) 64, 461-463; doi:10.1038/ja.2011.24; published online 30 March 2011

Keywords: biosynthetic engineering; geldanamycin; Hsp90 inhibitor; non-quinone geldanamycin

Heat shock protein 90 (Hsp90) is emerging as an important target in cancer therapeutics and several other diseases. ${ }^{1,2}$ Hsp90 is an abundant and ubiquitously expressed molecular chaperone that is involved in the maturation of multiple client proteins, many of which are involved in regulating cell signaling, proliferation and survival. ${ }^{3,4}$ Client proteins of Hsp90 include Her-2, Akt, Src, Abl, c-Met and Raf-1, which are currently being targeted for intervention within oncology drug discovery or in clinical development. Although Hsp90 is highly expressed in most cells, Hsp90 inhibitors display remarkable selectivity for cancer cells as compared with normal cells. ${ }^{5,6}$

Hsp90 is effectively inhibited by benzoquinone ansamycins such as geldanamycin (GM, 1), herbimycin, macbecin and many of their derivatives, which bind to the ATP-binding site in the $N$-terminal domain. ${ }^{7,8}$ However, the development of $\mathbf{1}$ as a clinical agent has so far been limited by its toxicity, especially liver toxicity. ${ }^{9}$ However, the promising antitumor properties of $\mathbf{1}$ have spurred initiatives to develop biologically active derivatives. ${ }^{10,11}$ 17-Allylamino-17demethoxyGM (17-AAG) has reduced toxicity compared with $\mathbf{1}$ and is the most advanced Hsp90 inhibitor in clinical development (Phase II/III). ${ }^{12}$ 17-AAG and its benzoquinone analogs conjugate with glutathione, leading to cellular depletion. This conjugation with sulfur-containing nucleophiles may contribute to the dose-limiting hepatotoxicity of these quinone-containing compounds. ${ }^{13,14}$ For these reasons, new non-quinone 1 analogs with improved pharmacological profiles are needed. ${ }^{15,16}$

Recently, we reported the development of non-quinone $\mathbf{1}$ analogs by a mutasynthetic approach and directed biosynthetic method. ${ }^{16,17}$ Of these non-quinone 1 analogs, DHQ3 (3), a 15-hydroxyl-17demethoxy non-quinone analog, was found to inhibit Hsp90 ATPase activity more than $1 .{ }^{16}$ Moreover, during these studies, novel tricyclic 1 analogs were prepared from a genetically engineered strain (AC15) of Streptomyces hygroscopicus. ${ }^{18}$ Presently, we describe the fermenta- tion of mutant $\mathrm{AC} 15$, and the isolation, structural determination and bioactivity of new non-quinone $\mathbf{1}$ analogs produced by the mutant: DHQ7 (4) and DHQ8 (5).

AC15 was constructed by a combinational mutation with site-directed mutagenesis of the first dehydratase domain of the geldanamycin polyketide synthase (PKS) gene ( $g e l A)$ and a post-PKS modification gene (gel7) of S. hygroscopicus JCM4427, as previously reported. ${ }^{16}$ The seed medium and production medium (YEME) consisted of sucrose $103.0 \mathrm{~g}$, yeast extract $3.0 \mathrm{~g}$, peptone (Difco, Sparks, MD, USA) $5.0 \mathrm{~g}$, malt extract (Difco) $3.0 \mathrm{~g}$, glucose $10.0 \mathrm{~g}$ and $\mathrm{MgCl}_{2} \cdot 6 \mathrm{H}_{2} \mathrm{O} 1.0 \mathrm{~g}$ in $1.0 \mathrm{l}$ of distilled water. Spores that developed during growth on ISP4 medium were harvested and inoculated into $300 \mathrm{ml}$ of YEME in a 1.01 baffled flask and cultured for 3 days at $28^{\circ} \mathrm{C}$. Equal volumes of the seed culture were inoculated into 25 baffled flasks containing $300 \mathrm{ml}$ of YEME medium. Fermentation was subsequently carried out for 7 days at $28^{\circ} \mathrm{C}$ and 160 r.p.m. The resulting culture $(\sim 81)$ was extracted twice with an equal volume of ethyl acetate (EtOAc). The extract was filtered through a fritted funnel and the resulting filtrate was evaporated in vacuo to yield the EtOAc extract. This extract was partitioned between EtOAc and water. The EtOAc-soluble material $(2.7 \mathrm{~g})$ was subjected to silica gel chromatography using a stepwise gradient elution of mixtures of $\mathrm{CH}_{2} \mathrm{Cl}_{2}$ and $\mathrm{MeOH}$. The fraction eluted with $\mathrm{CH}_{2} \mathrm{Cl}_{2}: \mathrm{MeOH}$ of $85: 15$ was further purified by reverse-phase HPLC using YMC-J'sphere ODS-H80 $\left(10 \times 250 \mathrm{~mm}, 3 \mathrm{ml} \mathrm{min}^{-1}\right.$; YMC, Kyoto, Japan $)$ with a linear gradient from 30 to $100 \%$ acetonitrile $(\mathrm{MeCN})$ containing $0.05 \%$ trifluoroacetic acid to yield DHQ7 $(4 ; 31.8 \mathrm{mg})$ and DHQ8 $(5 ; 17.6 \mathrm{mg})$. Compound 3 ( $317 \mathrm{mg}$ ) was purified from the fraction eluted with $\mathrm{CH}_{2} \mathrm{Cl}_{2}: \mathrm{MeOH}$ (90:10), subjected to passage over a Sephadex LH-20 (GE Healthcare, Buckinghamshire, UK) column using $\mathrm{MeOH}$ as eluant and further purified by HPLC (YMC J'sphere ODS-H80, 10×250 mm,

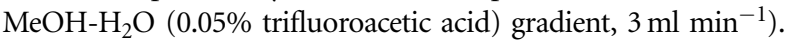

${ }^{1}$ KRIBB, 685-1 Yangcheong-ri, Ochang, Chungbuk, Korea; ${ }^{2}$ College of Pharmacy, Chungnam National University, Daejeon, Korea; ${ }^{3}$ Idong Pharmaceutical Co. Seoul, Korea; ${ }^{4}$ School of Life Sciences and Biotechnology, Korea University, Seoul, Korea and ${ }^{5}$ College of Pharmacy, Chungbuk National University, Cheongju, Korea 
The structures of known 3 were identified by spectral data interpretation and comparison with literature values. ${ }^{16,19}$ Compound 4 was obtained as a white powder $\left([\alpha]_{\mathrm{D}}^{27}+11.1(\mathrm{c}, 0.10, \mathrm{MeOH})\right.$; UV $(\mathrm{MeOH}) \lambda_{\max }(\log \varepsilon) 204$ (4.55), 260 (3.77), $289 \mathrm{~nm}$ (3.69)). The molecular formula was determined as $\mathrm{C}_{28} \mathrm{H}_{40} \mathrm{~N}_{2} \mathrm{O}_{8}$ from HR-ESIMS data (found, $m / z 555.2673[\mathrm{M}+\mathrm{Na}]^{+}$; calculated 555.2677 for $\mathrm{C}_{28} \mathrm{H}_{40} \mathrm{~N}_{2} \mathrm{NaO}_{8}$ ) in conjunction with NMR data. The ${ }^{13} \mathrm{C}$ NMR and HMQC spectra revealed the presence of 28 carbon signals comprising two carbonyl, six aromatic or olefinic quaternary, six aromatic or olefinic methine, four oxymethine, two aliphatic methine, two aliphatic methylene, two $O$-methyl, and four $C$-methyl carbons. Additionally, four exchangeable proton signals were observed in DMSO- $d_{6}$ : two hydroxyl protons ( $\delta 5.10$ and 4.76), one phenolic hydroxyl proton $(\delta$ 9.13) and one amide proton $(\delta$ 9.33). These physicochemical properties and NMR data suggested that 4 was related to 1 . Interpretation of the 2D-NMR data including COSY, HMQC and HMBC spectra enabled the construction of structure of 4 . Compound 4 displayed the characteristic paired signals including those of 3, suggesting that 4 is a modified 3 and contains a C-15 hydroxylated non-quinone 1 skeleton. Thus, the presence of three olefinic protons $((\delta 5.89(1 \mathrm{H}, \mathrm{dd}, J=4.8,7.2 \mathrm{~Hz}, \mathrm{H}-3), 5.47(1 \mathrm{H}, \mathrm{d}, J=9.2 \mathrm{~Hz}, \mathrm{H}-9)$, and $5.15(1 \mathrm{H}, \mathrm{d}, J=10.4 \mathrm{~Hz}, \mathrm{H}-12))$, and the corresponding carbon signals ( $\delta 136.73$ (C-3), $136.10(\mathrm{C}-9)$ and 111.86 (C-13)), indicated that one more position of $\mathbf{3}$ is unsaturated. The position of the newly formed double bond was confirmed using the HMBC NMR experiments (H-25/C-13 and C-14, H-14/C-13, H-13/C-12, 12- $\mathrm{OCH}_{3} / \mathrm{C}-12$, $\mathrm{H}-11 / \mathrm{C}-12)$. Therefore, the structure of this new C-15 hydroxylated non-quinone 1 analog 4 was assigned as shown in Figure 1.

DHQ8 (5) was also obtained as a white powder $\left([\alpha]_{\mathrm{D}}^{27}-24.8\right.$ (c, 0.10, MeOH); UV (MeOH) $\lambda_{\max }(\log \varepsilon) 203$ (4.43), 262 (3.70), $295 \mathrm{~nm}$ (3.62)), the molecular formula being established as $\mathrm{C}_{29} \mathrm{H}_{41} \mathrm{~N}_{3} \mathrm{O}_{9}$ on the basis of the HR-ESIMS data (found, $\mathrm{m} / z$ $598.2733[\mathrm{M}+\mathrm{Na}]^{+}$; calculated 598.2735 for $\mathrm{C}_{29} \mathrm{H}_{41} \mathrm{~N}_{3} \mathrm{NaO}_{9}$ ) and NMR data. The ${ }^{1} \mathrm{H}$ and ${ }^{13} \mathrm{C}$ NMR spectra of 5 were very similar to those of 4 (Table 1), except for the absence of one hydroxyl signal and the additional carbamoyl signal at $\delta_{\mathrm{C}} 156.95$ in the later compound, and were consistent with the molecular formula $\mathrm{C}_{29} \mathrm{H}_{41} \mathrm{~N}_{3} \mathrm{O}_{9}$ obtained by positive HR-ESIMS. The position of these carbamoyl groups was determined by HMBC correlations (H-7/7-OCONH$H_{2}$ and $\mathrm{H}-11 /$ 11- $\mathrm{OCONH}_{2}$ ). Further interpretation of the $2 \overline{\mathrm{D}} \mathrm{NMR}$ data led to the structure of 5 .

All isolated compounds (3, 4 and $\mathbf{5})$ were tested for the ability to inhibit yeast Hsp90 activity using a malachite green ATPase assay. Compounds $\mathbf{4}$ and $\mathbf{5}$ showed potent activity of ATPase inhibition with $\mathrm{IC}_{50}$ values of 1.75 and $5.87 \mu \mathrm{M}$, respectively. But, the 3 showed stronger ATPase inhibition activity $(0.68 \mu \mathrm{M})$ compared with the original Hsp90 inhibitor $1(3.19 \mu \mathrm{M})$, as previously demonstrated. ${ }^{16}$
To further confirm that $\mathbf{4}$ and $\mathbf{5}$ bind and interact with the $\mathrm{N}$-terminal nucleotide binding site of Hsp90 as an ATP mimetic, we examined whether these compounds could compete with a bead-immobilized derivative of ATP for Hsp90 binding. It is noteworthy that the compounds demonstrated significant activity compared with the DMSO control. However, the concentration of competitive binding did not exactly match the values of the previous ATPase assay. But, this

\section{Table 1 NMR data of DHQ7 (4) and DHQ8 (5) in DMSO- $d_{6}$}

\begin{tabular}{|c|c|c|c|c|}
\hline & \multicolumn{2}{|c|}{$\delta C$} & \multicolumn{2}{|c|}{$\delta H$} \\
\hline & 4 & 5 & 4 & 5 \\
\hline 1 & $168.32 \mathrm{~s}$ & $168.45 \mathrm{~s}$ & & \\
\hline 2 & $132.43 \mathrm{~s}$ & $132.05 \mathrm{~s}$ & & \\
\hline 3 & $136.73 \mathrm{~d}$ & $136.90 \mathrm{~d}$ & $5.89 \mathrm{dd}(4.8,7.2)$ & 6.01 t (6.0) \\
\hline 4 & $23.75 \mathrm{t}$ & $23.92 \mathrm{t}$ & $2.12 \mathrm{~m} ; 2.23 \mathrm{~m}$ & $2.15 \mathrm{~m}$ \\
\hline 5 & $30.64 t$ & $30.80 \mathrm{t}$ & $1.42 \mathrm{~m} ; 1.62 \mathrm{~m}$ & $1.33 \mathrm{~m} ; 1.45 \mathrm{~m}$ \\
\hline 6 & $79.89 \mathrm{~d}$ & $80.60 \mathrm{~d}$ & 2.96 t (8.4) & $3.22 \mathrm{~m}$ \\
\hline 7 & $81.14 \mathrm{~d}$ & $81.40 \mathrm{~d}$ & $4.80 \mathrm{~d}(4.8)$ & $4.79 \mathrm{~d}(8.8)$ \\
\hline 8 & $130.02 \mathrm{~s}$ & $131.93 \mathrm{~s}$ & & \\
\hline 9 & $136.10 \mathrm{~d}$ & $133.47 \mathrm{~d}$ & $5.47 \mathrm{~d}(9.2)$ & $5.31 \mathrm{~d}(10.4)$ \\
\hline 10 & $32.66 \mathrm{~d}$ & $31.60 \mathrm{~d}$ & $2.57 \mathrm{~m}$ & $2.82 \mathrm{~m}$ \\
\hline 11 & $71.83 \mathrm{~d}$ & $73.70 \mathrm{~d}$ & $3.88 \mathrm{~d}(4.8)$ & 4.98 brs \\
\hline 12 & $154.98 \mathrm{~s}$ & $150.26 \mathrm{~s}$ & & \\
\hline 13 & $111.86 \mathrm{~d}$ & $112.64 \mathrm{~d}$ & $5.15 \mathrm{~d}(10.4)$ & $5.01 \mathrm{~d}(10.4)$ \\
\hline 14 & $37.35 \mathrm{~d}$ & $37.39 \mathrm{~d}$ & $2.57 \mathrm{~m}$ & $2.53 \mathrm{~m}$ \\
\hline 15 & $76.75 \mathrm{~d}$ & $76.75 \mathrm{~d}$ & $4.39 \mathrm{brs}$ & $4.34 \mathrm{brs}$ \\
\hline 16 & $146.80 \mathrm{~s}$ & $146.86 \mathrm{~s}$ & & \\
\hline 17 & $108.07 \mathrm{~d}$ & $108.42 \mathrm{~d}$ & $6.27 \mathrm{~s}$ & $6.26 \mathrm{~s}$ \\
\hline 18 & $156.86 \mathrm{~s}$ & $156.93 \mathrm{~s}$ & & \\
\hline 19 & $103.76 \mathrm{~d}$ & $103.48 d$ & $7.49 \mathrm{~s}$ & $7.48 \mathrm{~s}$ \\
\hline 20 & $139.42 \mathrm{~s}$ & $139.50 \mathrm{~s}$ & & \\
\hline 21 & $110.25 d$ & $109.35 \mathrm{~d}$ & $6.73 \mathrm{~s}$ & $6.48 \mathrm{~s}$ \\
\hline 22 & $12.62 \mathrm{q}$ & $12.48 \mathrm{q}$ & $1.78 \mathrm{~s}$ & $1.75 \mathrm{~s}$ \\
\hline 23 & $11.47 \mathrm{q}$ & $11.64 \mathrm{q}$ & $1.50 \mathrm{~s}$ & $1.59 \mathrm{~s}$ \\
\hline 24 & $12.17 \mathrm{q}$ & $12.80 \mathrm{q}$ & $0.77 \mathrm{~d}(6.4)$ & $0.88 \mathrm{~d}(7.2)$ \\
\hline 25 & $18.71 \mathrm{q}$ & $19.07 \mathrm{q}$ & $1.10 \mathrm{~d}(6.8)$ & $1.11 \mathrm{~d}(6.8)$ \\
\hline $6-\mathrm{OCH}_{3}$ & $59.21 \mathrm{q}$ & $58.74 \mathrm{q}$ & $3.38 \mathrm{~s}$ & $3.37 \mathrm{~s}$ \\
\hline $12-\mathrm{OCH}_{3}$ & $56.57 \mathrm{q}$ & $56.66 \mathrm{q}$ & $2.68 \mathrm{~s}$ & $2.77 \mathrm{~s}$ \\
\hline 7-OCONH & $156.05 \mathrm{~s}$ & $155.99 \mathrm{~s}$ & & \\
\hline $11-\mathrm{OCONH}_{2}$ & & $156.95 \mathrm{~s}$ & & \\
\hline $11-\mathrm{OH}$ & & & $4.76 \mathrm{~d}(5.6)$ & \\
\hline $15-\mathrm{OH}$ & & & $5.10 \mathrm{~d}(2.8)$ & $5.07 \mathrm{~d}(3.2)$ \\
\hline $18-\mathrm{OH}$ & & & $9.13 \mathrm{~s}$ & $9.19 \mathrm{~s}$ \\
\hline $\mathrm{NH}$ & & & $9.33 \mathrm{~s}$ & $9.22 \mathrm{~s}$ \\
\hline
\end{tabular}

Chemical shifts are shown in the $\delta$ scale with $J$ values $(H z)$ in parentheses.

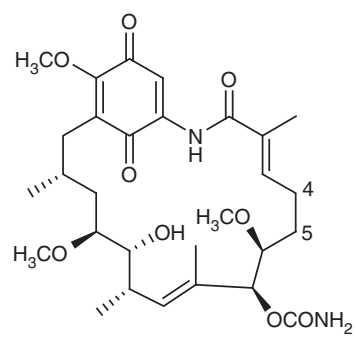

Geldanamycin (1), $\Delta^{4(5)}$ 4,5-dihydrogeldanmycin (2)

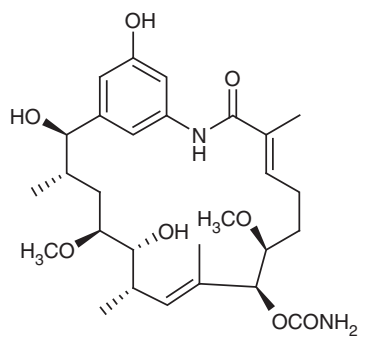

DHQ3 (3)

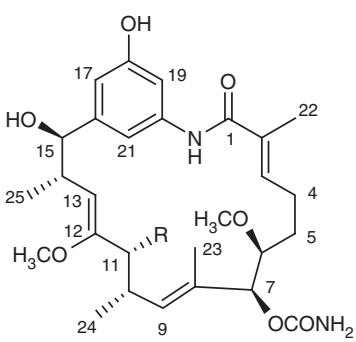

DHQ7 (4) $\mathrm{R}=\mathrm{OH}$ $\mathrm{DHQ} 8$ (5) $\mathrm{R}=\mathrm{OCONH}_{2}$

Figure 1 Chemical structures of geldanamycin (1), 4,5-dihydrogeldanamycin (2), DHQ3 (3), DHQ7 (4) and DHQ8 (5). 
Table 2 Comparison of biological activities of geldanamycin, DHQ3, DHQ7 and DHQ8

\begin{tabular}{|c|c|c|c|c|}
\hline \multirow[b]{2}{*}{ Compounds } & \multirow[b]{2}{*}{$\begin{array}{l}\text { Yeast Hsp90 ATPase } \\
\text { inhibition assay }\left({ } C_{50}\right)\end{array}$} & \multicolumn{3}{|c|}{ Cell viability assay $\left(I C_{50}\right)$} \\
\hline & & A2780 & SK-Br3 & BT474 \\
\hline Geldanamycin (1) & $3.19 \mu \mathrm{M}$ & $7 \mathrm{~nm}$ & $9 \mathrm{~nm}$ & $5 \mathrm{~nm}$ \\
\hline DHQ3 (3) & $0.68 \mu \mathrm{M}$ & $24 \mu \mathrm{M}$ & $40 \mu \mathrm{m}$ & $16 \mu \mathrm{m}$ \\
\hline DHQ7 (4) & $1.75 \mu \mathrm{M}$ & $13 \mu \mathrm{m}$ & $15 \mu \mathrm{m}$ & $8 \mu \mathrm{m}$ \\
\hline DHQ8 (5) & $5.87 \mu \mathrm{M}$ & $17 \mu \mathrm{M}$ & $173 \mu \mathrm{m}$ & $63 \mu \mathrm{m}$ \\
\hline
\end{tabular}

A2780, human ovarian cancer cell; SK-Br3 and BT474, human breast cancer cell.

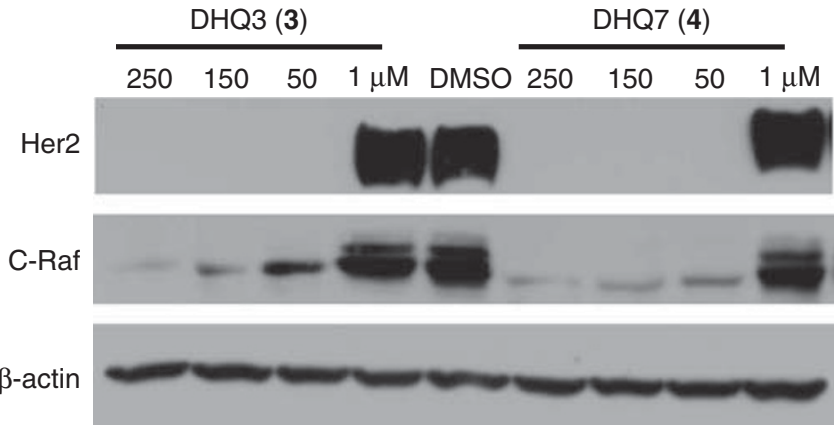

Figure 2 Non-quinone geldanamycin derivatives (DHQ3 (3) and DHQ7 (4)) destabilize Hsp90 client proteins (Her2 and c-Raf). SK-Br3 cells were treated with $\mathbf{3}$ and $\mathbf{4}$ for $24 \mathrm{~h}$ at increasing doses. Her2 and c-Raf levels were analyzed by western blotting.

finding confirmed that non-quinone $\mathbf{1}$ analogs also interact with the nucleotide-binding site of Hsp90 (Supplementary data).

The non-quinone 1 analogs were evaluated for their anti-proliferation activity using tumor cell growth inhibition assays in human ovarian A2780 and breast SK-Br3 and BT474 cancer cell lines, following the standard procedures. 4 showed anti-proliferative activity against A2780, SK-Br3 and BT474 cells at 13, 15 and $8 \mu \mathrm{M}$, respectively, whereas 5 was less effective in the cancer cell lines. In contrast, 1 showed sub- $\mu \mathrm{M}$ cytotoxic activity against several human cancer cells (Table 2). The antiproliferation activity data showed that $\mathrm{C}-15$ hydroxylated non-quinone $\mathbf{1}$ analogs exhibited a potency that was weak and less than that of $\mathbf{1}$. Further carbamoylation at the C11 hydroxy position did not show improvement in the anti-proliferative activities. In addition to antiproliferation activity studies, we further examined whether Her2 and c-Raf, well-documented clients of Hsp90, were degraded by 3 and 4 . As shown in Figure 2, western blot analysis indicated that Her2 and c-Raf were degraded by the inhibitors in a concentration-dependent manner. Therefore, the non-quinone $\mathbf{1}$ seemed to have an anti-proliferative effect via $\mathrm{Hsp} 90$ inhibition in $\mathrm{Sk}-\mathrm{Br} 3$ cells.

Although these non-quinone 1 derivatives showed favorable potency in the ATPase assay, its lack of potency in the cellular assays was found. The reason for this discrepancy between ATPase inhibition activity and anti-proliferative activities is not clear. But, we expect that further development of semi-synthetic derivatives with more diverse residues, such as diaminoalky functionality introduced at the benzene ring and/or C15-position, ${ }^{20}$ may exhibit improved cellular potency over 4 or 5 .

\section{ACKNOWLEDGEMENTS}

This work was supported in part by the 21C Frontier Microbial Genomics and Application Center and Global R\&D Center program, the Ministry of Science and Technology, Republic of Korea and by a grant from KRIBB Research Initiative Program. We thank the Korea Basic Science Institute for the NMR measurements

1 Janin, Y. L. ATPase inhibitors of heat-shock protein 90, second season. Drug Discov. Today. 15, 342-353 (2010).

2 Whitesell, L. \& Lindquist, S. L. HSP90 and the chaperoning of cancer. Nat. Rev. Cancer. 5, 761-772 (2005)

3 Prodromou, C. \& Pearl, L. H. Structure and functional relationships of Hsp90. Curr. Cancer Drug Targets. 3, 301-323 (2003).

4 Bishop, S. C., Burlison, J. A. \& Blagg, B. S. Hsp90: a novel target for the disruption of multiple signaling cascades. Curr. Cancer Drug Targets. 7, 369-388 (2007).

5 Kamal, A. et al. A high-affinity conformation of Hsp90 confers tumour selectivity on Hsp90 inhibitors. Nature 425, 407-410 (2003).

6 Neckers, L. \& Lee, Y. S. Cancer: the rules of attraction. Nature 425, 357-359 (2003).

7 Whitesell, L., Mimnaugh, E. G., De Costa, B., Myers, C. E. \& Neckers, L. M. Inhibition of heat shock protein HSP90-pp60v-src heteroprotein complex formation by benzoquinone ansamycins: essential role for stress proteins in oncogenic transformation. Proc. Natl Acad. Sci. USA. 91, 8324-8328 (1994).

8 Panaretou, B. et al. ATP binding and hydrolysis are essential to the function of the Hsp90molecular chaperone in vivo. EMBO J. 17, 4829-4836 (1998).

9 Supko, J. G., Hickman, R. L., Grever, M. R. \& Malspeis, L. Preclinical pharmacologic evaluation of geldanamycin as an antitumor agent. Cancer Chemother. Pharmacol. 36, 305-315 (1995).

10 Taldone, T., Sun, W. \& Chiosis, G. Discovery and development of heat shock protein 90 inhibitors. Bioorg. Med. Chem. 17, 2225-2235 (2009).

11 Neckers, L. \& Neckers, K. Heat-shock protein 90 inhibitors as novel cancer chemotherapeutics - an update. Expert Opin. Emerg Drugs. 10, 137-149 (2005).

12 Heath, E. I. et al. A phase II trial of 17-allylamino-17-demethoxygeldanamycin in patients with hormone-refractory metastatic prostate cancer. Clin. Cancer Res. 14, 7940-7946 (2008).

13 Cysyk, R. L., Parker, R. J., Barchi, J. J. Jr., Steeg, P. S., Hartman, N. R. \& Strong, J. M. Reaction of geldanamycin and $\mathrm{C} 17$-substituted analogues with glutathione: product identifications and pharmacological implications. Chem. Res. Toxicol. 19, 376-381 (2006)

14 Maroney, A. C. et al. Dihydroquinone ansamycins: toward resolving the conflict between low in vitro affinity and high cellular potency of geldanamycin derivatives. Biochemistry 45, 5678-5685 (2006).

15 Zhang, M. Q. et al. Optimizing natural products by biosynthetic engineering: discovery of nonquinone Hsp90 inhibitors. J. Med. Chem. 51, 5494-5497 (2008).

$16 \mathrm{Kim}, \mathrm{W}$. et al. Rational biosynthetic engineering for optimization of geldanamycin analogues. ChemBioChem. 10, 1243-1251 (2009).

$17 \mathrm{Kim}, \mathrm{W}$. et al. Mutasynthesis of geldanamycin by the disruption of a gene producing starter unit: generation of structural diversity at the benzoquinone ring. ChemBioChem. 8, 1491-1494 (2007)

18 Hong, S. S. et al. New tricyclic geldanamycin analogues from an engineered strain of Streptomyces hygroscopicus JCM4427. Tetrahedron Lett. 51, 351-353 (2010).

19 Lee, D. et al. Biosynthesis of the heat-shock protein 90 inhibitor geldanamycin: new insight into the formation of the benzoquinone moiety. ChemBioChem. 7, 246-248 (2006).

20 Lee, K. et al. Synthesis and anticancer activity of geldanamycin derivatives derived from biosynthetically generated metabolites. Org. Biomol. Chem. 6, 340-348 (2008).

Supplementary Information accompanies the paper on The Journal of Antibiotics website (http://www.nature.com/ja) 